\title{
Perspectives of Treatment Consumers, Treatment Providers, and Law Enforcement on Drug Treatment and Prevention
}

\author{
Shauna P. Acquavita ${ }^{1,2}$; Linnea Lowe ${ }^{1}$; Kayleigh Fiser ${ }^{3}$; R. Thomas Sherba ${ }^{4}$ \\ ${ }^{1}$ School of Social Work, University of Cincinnati, Cincinnati, $\mathrm{OH}$ \\ ${ }^{2}$ Center for Addiction Research, University of Cincinnati, Cincinnati, $\mathrm{OH}$ \\ ${ }^{3}$ Department of Health Promotions, University of Cincinnati, Cincinnati, OH \\ ${ }^{4}$ Office of Quality, Planning and Research, Ohio Department of Mental Health and Addiction Services \\ Corresponding Author: Shauna P. Acquavita, P.O. Box 670108, Cincinnati, OH 45267, (513) 556-4619, acquavsa@ucmail.uc.edu \\ Submitted May 6, 2021 Accepted November 1, 2021 Published January 28, 2022 https://doi.org/10.18061/ojph.v4i2.8299
}

\section{ABSTRACT}

Background: While much of the literature has focused on examining barriers to substance use disorders (SUD) treatment with individuals with SUD, there is a dearth of research from the perspective of treatment providers and law enforcement, 2 groups who witness the challenges for addressing SUD.

Methods: Using content analysis, this qualitative study explored the perspectives of individuals with SUD, treatment providers, and law enforcement on recommendations about SUD treatment and prevention. Data from 12 focus groups with individuals with SUD were analyzed and triangulated with interviews from treatment providers and law enforcement. Cross case analysis was utilized to identify common categories.

Results: The categories identified included education, judicial system, psychosocial barriers, resources, stigma, stages of change, and treatment. Results indicated all groups had similar ideas on how to address SUD. Participants provided recommendations in each category for addressing SUD.

Conclusion: Individuals with SUD, treatment providers, and law enforcement officers are affected by complex issues of SUD on micro, mezzo, and macro levels. Public health professionals can help to facilitate changes by advocating for prevention and intervention methods to be implemented to address SUD.

Keywords: Substance use disorders; Law enforcement; Treatment providers; Focus groups

\section{INTRODUCTION}

In 2017, an estimated 21.2 million Americans needed substance use disorders (SUD) treatment, yet only an estimated 3.7 million received treatment. ${ }^{1}$ For individuals, families, and communities, SUD are associated with adverse outcomes such as medical and mental health conditions, lost wages, and criminal activity. ${ }^{2}$ Community and governmental responses to SUDs have addressed them as public health and criminal justice matters.,3 While street-level enforcement strategies such as arrests have been the standard response toward illicit drug use, ${ }^{5}$ public health responses address- ing prevention, treatment, and harm reduction have been popular in recent decades. These include screening, brief intervention and referral to treatment, 6 medication treatment, ${ }^{7}$ and harm reduction approaches such as support programs, resources on safer ways to use substances, take-home naloxone kits, supervised consumption services, ${ }^{8,9}$ and syringe exchange programs. ${ }^{10}$

\section{Ohio State and Regional Trends}

From 2007 to 2018, drug overdose was the leading cause of death from planned and unplanned injuries in Ohio.11 Ohio has the fifthhighest overdose death rate in the nation, ${ }^{12}$ with an age-adjusted 
overdose death rate of 35.9 , as compared to a national average of 20.7.13 The Cincinnati region, as identified by the Ohio Substance Abuse Monitoring Network (OSAM), encompasses 13 counties in Southwest Ohio. ${ }^{14}$ Death rates by unintentional drug overdoses range from 23.6 to 53.3 per 100000 people in these counties. ${ }^{15}$

\section{Study Background}

Research on barriers to SUD treatment has predominantly been conducted with individuals with SUD. Limited research has been explored with the counselors and therapists providing SUD treatment or with the law enforcement officials enforcing substance use laws and policies.3,16 Counselors provide an essential perspective to the discussion, as they are privy to the challenges of SUD treatment delivery and maintain connections to those receiving treatment. ${ }^{16}$ Research with law enforcement populations can offer insights, as they have wide discretion in how they enforce the law. ${ }^{17}$ Furthermore, the criminal justice system has served as a primary service delivery system for adults facing the challenges of SUD. ${ }^{17}$ This study contributes to the underdeveloped literature investigating law enforcement officers' attitudes toward drug use and treatment.

\section{Study Purpose}

Established in 1999, the OSAM Network is a prospective, longitudinal study of illicit and prescription drug abuse in Ohio. ${ }^{18}$ Regional epidemiologists conduct focus groups with persons receiving SUD treatment (treatment consumers). These focus group findings are cross-referenced with findings from individual interviews and focus groups conducted with community professionals who provide SUD prevention/treatment services (ie, social workers and counselors/therapists), as well as with those whose work is directly impacted by substance use disorders (ie, law enforcement, probation officers, and coroners). Once integrated, these data provide Ohio's behavioral health authority, Ohio Mental Health and Addiction Services (OhioMHAS), real-time, epidemiologic descriptions that policymakers need to plan prevention and intervention strategies. This study was a smaller examination of a larger study that OSAM conducts twice a year to monitor drug trends in specific regions. Our study examined a focus group question that was not analyzed in the larger study.

The research question analyzed for this study was: "Imagine you could speak to the governor and other state officials right now. What recommendations regarding drug abuse prevention and treatment, specific to this region, would you make?"

\section{METHODS}

This expedited study was approved by the institutional review board. Participants included individuals who were using illicit drugs or had stopped using illicit drugs within 6 months prior to study enrollment, treatment providers who provided SUD treatment, and law enforcement officers. Focus groups and interviews occurred August 2018 through May 2019.

\section{Setting and Design}

Recruitment occurred by the first author calling SUD facilities and law enforcement in the region and requesting their participation. Agencies then received an email with a flyer to distribute with information about the study, location, date and time of group, and incentive payment.

Focus groups $(\mathrm{n}=12)$ were implemented at SUD residential, intensive outpatient, and outpatient treatment centers. Eligible participants were individuals receiving treatment for SUD aged 18 years or older who spoke English and had less than 6 months in recovery from SUD. Participants were provided a $\$ 20$ gift card to a local store.

Providers and law enforcement were interviewed individually or in focus groups at their location or at a location such as a library. Treatment providers and law enforcement were eligible if they were working at a SUD treatment facility or in law enforcement and had knowledge on drug abuse in Ohio within the past 6 months. Due to ethical considerations, treatment providers and law enforcement did not receive monetary compensation. Three focus groups and 1 interview occurred with treatment providers. Three interviews and 1 focus group took place with law enforcement officers.

\section{Participants}

Eighty-nine treatment consumers, 18 treatment providers, and 8 individuals in law enforcement were interviewed regarding drug abuse prevention and treatment. The interviews and focus groups were conducted in 5 counties in Ohio: Butler, Clermont, Clinton, Hamilton and Warren. Focus groups ranged from 4 to 12 participants per group of treatment consumers. Table 1 describes the demographics of the treatment consumers. Missing data included 2 participants not answering questions on income and poverty status and 1 participant not answering questions on ethnicity and graduation rate. Demographic information of providers and law enforcement were unavailable.

\section{Procedures}

Focus groups for treatment consumers were conducted in a room at the SUD treatment center between or after SUD treatment groups. Before the start of the focus group, participants were screened for eligibility, informed the interview would be recorded, assured of anonymity, and assured treatment would not be impacted if they declined or decided to participate. Confidentiality among focus group participants was also stressed. Participation consent was then obtained. Participants completed a demographic survey prior to the start of the focus group. The focus groups were facilitated by the first author with a coauthor present to observe and take notes. A debriefing session was held by the researchers after each focus group to discuss observations and record field notes.

Interviews with treatment providers and law enforcement occurred with the first author. Similar to procedures with treatment 
consumer participants, screening for eligibility, consent, request to record the interview, and assurance of anonymity of responses occurred. The first author documented field notes after each interview.

\section{Data Analysis}

The audio recordings of the interviews and focus groups were transcribed verbatim by the second author. Participants were deidentified. The transcriptions were read by the first author to check for consistency. Qualitative content analysis process was used to analyze the data. ${ }^{19}$ Through an iterative process, the research team constructed a qualitative coding scheme, which was applied to the interview transcripts. ${ }^{20}$ As themes emerged from the data, they were added to the scheme, which allowed for inductive analysis. ${ }^{21}$

Transcripts from the treatment consumers were reviewed by the first 3 authors independently to identify common codes though an iterative process. Next, preliminary codes were identified. The first 3 authors then met and developed a codebook. These authors recoded the transcripts with the codebook and discussed any discrepancies. After reaching saturation with the treatment consumers disorders transcripts, the authors triangulated the data ${ }^{22}$ by utilizing cross case analysis ${ }^{23}$ with the treatment providers and law enforcement transcripts. Peer debriefing ${ }^{24}$ also occurred.

\section{Table 1. Demographics}

\begin{tabular}{|c|c|c|}
\hline Characteristic & $\mathbf{N}$ & $\%$ \\
\hline \multicolumn{3}{|l|}{ Gender } \\
\hline Male & 50 & $56 \%$ \\
\hline Female & 39 & \\
\hline \multicolumn{3}{|l|}{ Race } \\
\hline White & 68 & $76 \%$ \\
\hline African American & 20 & \\
\hline \multicolumn{3}{|l|}{ Ethnicity } \\
\hline Latinx & 4 & $4 \%$ \\
\hline \multicolumn{3}{|l|}{ Age in years } \\
\hline$<20$ & 1 & $1 \%$ \\
\hline $20-29$ & 12 & $13 \%$ \\
\hline $30-39$ & 36 & $40 \%$ \\
\hline $40-49$ & 12 & $13 \%$ \\
\hline $50-59$ & 23 & $26 \%$ \\
\hline$\geq 60$ & 5 & $6 \%$ \\
\hline \multicolumn{3}{|l|}{ Education } \\
\hline Less than high school graduate & 22 & $25 \%$ \\
\hline High school graduate & 32 & $36 \%$ \\
\hline Some college or associate degree & 29 & $33 \%$ \\
\hline Bachelor's degree or higher & 5 & $6 \%$ \\
\hline \multicolumn{3}{|l|}{ Household income } \\
\hline$<\$ 12000$ & 37 & $42 \%$ \\
\hline$\$ 12000$ to $\$ 20999$ & 17 & $19 \%$ \\
\hline$\$ 21000$ to $\$ 28999$ & 12 & $13 \%$ \\
\hline$\$ 29000$ to $\$ 37999$ & 8 & $9 \%$ \\
\hline$\geq \$ 38000$ & 11 & $12 \%$ \\
\hline \multicolumn{3}{|l|}{ Drug of choice } \\
\hline Alcohol & 31 & $35 \%$ \\
\hline Cocaine, crack & 17 & $19 \%$ \\
\hline Cocaine, powdered & 16 & $18 \%$ \\
\hline Ecstacy/Molly & 6 & $7 \%$ \\
\hline Heroin/Fetanyl & 31 & $35 \%$ \\
\hline Marijuana & 32 & $36 \%$ \\
\hline Methamphetamine & 23 & $26 \%$ \\
\hline Prescription opioids & 26 & $29 \%$ \\
\hline Prescription stimulants & 9 & $10 \%$ \\
\hline Sedative-hypnotics & 18 & $20 \%$ \\
\hline Suboxone ${ }^{\circledR} /$ Subutex ${ }^{\circledR}$ & 25 & $28 \%$ \\
\hline Other drugs* & 4 & $4 \%$ \\
\hline
\end{tabular}

Sample Description $(n=89)$

Not all participants filled out forms completely; therefore, numbers may not equal total participants.

Some respondents reported multiple drugs of use during the past 6 months.

*lysergic acid diethylamide (LSD) and dextromethorphan cough syrup (DXM) 


\section{RESULTS}

Codes were identified in each focus group that overlapped with all groups conducted. Table 2 provides information on codes and categories, whereby the specific codes were identified by participant group and specific transcript $(\mathrm{C}=$ clients, $\mathrm{P}=$ providers, $\mathrm{L}=\mathrm{law}$ enforcement). Overall, recommendations regarding drug abuse prevention and treatment in Ohio overlapped for treatment consumers, treatment providers, and law enforcement. Eight categories were identified.

\section{Access to Care}

Treatment consumers reported the biggest barrier to SUD treatment was access to care: "More availability ... there needs to be more bed space." They discussed how they could not get the help they needed in a timely manner. Treatment providers also reported this issue and discussed how they had to provide a lower level of treatment until the treatment consumers could be admitted. "We have patients that come into our program and we are just not providing them the services they need." Law enforcement also saw a great need for treatment. "We need easier access to providers." In- surance, or lack thereof, was discussed. This included private and Medicaid, as Ohio has state-run Medicaid insurance. Many treatment consumers lose their jobs, rendering them without insurance. A treatment consumer summarized the problem succinctly: "A lot of rehabs only accept private insurance, and a lot of the people that are doing drugs won't have insurance." Treatment providers talked about the time it took to get a client to get Medicaid, their frustration with the system, as well as their concern that clients would not be able to stay alive long enough to get treatment: "Our clients are struggling to stay alive [while] waiting for Medicaid to go through." Even those who did have benefits did not always have access to care: "[I'm] here [in treatment at a community agency] because the VA is too busy right now." Recommendations focused on bringing more SUD treatment providers to rural areas, changing the process to more quickly get Medicaid coverage for individuals who need SUD treatment services, and providing more and longer-term treatment at different care levels so that treatment accessed is appropriate to the individual's severity of SUD regardless of their insurance provider or ability to pay.

Table 2. Categories and Codes

\begin{tabular}{|c|c|c|c|c|c|}
\hline \multirow[t]{2}{*}{ Categories } & \multirow[t]{2}{*}{ Definition } & \multirow{2}{*}{$\begin{array}{l}\text { Codes collapsed into } \\
\text { categories }\end{array}$} & \multicolumn{3}{|c|}{ Found in focus groups or interviews with } \\
\hline & & & $\begin{array}{l}\text { Treatment } \\
\text { consumers }\end{array}$ & $\begin{array}{l}\text { Treatment } \\
\text { providers }\end{array}$ & $\begin{array}{l}\text { Law } \\
\text { enforcement }\end{array}$ \\
\hline Access to care & $\begin{array}{l}\text { Ability to get treatment that is } \\
\text { needed }\end{array}$ & Access, Insurance & $\begin{array}{l}1 \mathrm{C}, 2 \mathrm{C}, 4 \mathrm{C}, 5 \mathrm{C}, 6 \mathrm{C}, 7 \mathrm{C} \\
8 \mathrm{C}, 9 \mathrm{C}, 10 \mathrm{C}, 11 \mathrm{C}\end{array}$ & $1 \mathrm{P}, 2 \mathrm{P}, 3 \mathrm{P}$ & $1 \mathrm{~L}, 3 \mathrm{~L}$ \\
\hline Education & $\begin{array}{l}\text { Lack of preparation and } \\
\text { knowledge regarding SUD, } \\
\text { drugs and alcohol, and addic- } \\
\text { tion provided to individuals in } \\
\text { the school system, family } \\
\text { members/ friends of those } \\
\text { with SUD }\end{array}$ & Prevention, Lack of education & $\begin{array}{l}1 C, 2 C, 5 C, 6 C, 7 C, 8 C \\
9 C, 10 C, 11 C, 12 C\end{array}$ & $2 \mathrm{P}, 4 \mathrm{P}$ & $1 \mathrm{~L}, 2 \mathrm{~L}, 3 \mathrm{~L}, 4 \mathrm{~L}$ \\
\hline $\begin{array}{l}\text { Judicial } \\
\text { system }\end{array}$ & $\begin{array}{l}\text { Refers to laws, jail, or anything } \\
\text { related to legal system }\end{array}$ & Jails, Decriminalization & $\begin{array}{l}3 C, 5 C, 6 C, 7 C, 8 C \\
9 C, 10 C, 11 C, 12 C\end{array}$ & $3 \mathrm{P}$ & $1 \mathrm{~L}, 2 \mathrm{~L}, 3 \mathrm{~L}$ \\
\hline $\begin{array}{l}\text { Environmental } \\
\text { barriers }\end{array}$ & $\begin{array}{l}\text { Environmental factors that } \\
\text { impede recovery }\end{array}$ & $\begin{array}{l}\text { Unemployment, Housing, } \\
\text { Homelessness, Transportation }\end{array}$ & $\begin{array}{l}2 C, 4 C, 5 C, 6 C, 7 C \\
9 C, 11 C\end{array}$ & $1 \mathrm{P}, 3 \mathrm{P}, 4 \mathrm{P}$ & $2 \mathrm{~L}, 3 \mathrm{~L}$ \\
\hline Resources & $\begin{array}{l}\text { Providing outside support } \\
\text { through services and material } \\
\text { goods }\end{array}$ & $\begin{array}{l}\text { Finances, Material goods, Allo- } \\
\text { cation of money, Case man- } \\
\text { agement, Community engage- } \\
\text { ment, Advocacy, } \\
\text { Outreach, Insurance }\end{array}$ & $\begin{array}{l}2 C, 3 C, 4 C, 5 C, 6 C, 7 C \\
8 C, 9 C, 10 C, 11 C, 12 C\end{array}$ & $1 \mathrm{P}, 2 \mathrm{P}, 3 \mathrm{P}, 4 \mathrm{P}$ & $1 \mathrm{~L}, 2 \mathrm{~L}, 3 \mathrm{~L}, 4 \mathrm{~L}$ \\
\hline Stigma & $\begin{array}{l}\text { Negative perception of those } \\
\text { treatment consumers }\end{array}$ & Stigma, Isolation & $\begin{array}{l}1 C, 2 C, 6 C, 8 C, 10 C \\
9 C, 12 C\end{array}$ & $2 \mathrm{P}, 3 \mathrm{P}, 4 \mathrm{P}$ & $1 \mathrm{~L}, 2 \mathrm{~L}, 3 \mathrm{~L}$ \\
\hline $\begin{array}{l}\text { Stages of } \\
\text { change }\end{array}$ & $\begin{array}{l}\text { How ready is the individual to } \\
\text { receive treatment }\end{array}$ & Readiness to change & $\begin{array}{l}1 C, 2 C, 3 C, 4 C, 5 C, 6 C \\
7 C, 8 C, 10 C, 9 C, 11 C, 12 C\end{array}$ & $3 P$ & $2 \mathrm{~L}, 3 \mathrm{~L}$ \\
\hline Treatment & $\begin{array}{l}\text { The type of services a client } \\
\text { receives to aid in addressing } \\
\text { SUD }\end{array}$ & $\begin{array}{l}\text { Medication-assisted treatment, } \\
\text { Therapies, Integrated health, } \\
\text { Sober living }\end{array}$ & $\begin{array}{l}1 C, 2 C, 3 C, 4 C, 5 C, 6 C \\
7 C, 8 C, 9 C, 10 C, 11 C, 12 C\end{array}$ & $1 \mathrm{P}, 2 \mathrm{P}, 3 \mathrm{P}, 4 \mathrm{P}$ & $1 \mathrm{~L}, 2 \mathrm{~L}, 3 \mathrm{~L}, 4 \mathrm{~L}$ \\
\hline
\end{tabular}

Note: Transcripts analyzed for categories and codes are indicated by number and group. $\mathrm{C}=$ clients, $\mathrm{P}=$ providers, $\mathrm{L}=$ law enforcement 


\section{Education}

Treatment consumers, treatment providers, and law enforcement saw a need to educate the public. All groups agreed that: "Prevention has to start at a young age" (law enforcement). It was suggested that education take place in schools. Treatment consumers who were in recovery thought they should be a part of this process: "Maybe start having some recovering addicts go and speak to kids." Educating parents on how to talk about SUD with their children was recommended. Using media and venues such as community centers and churches were discussed. Furthermore, medical professionals need to provide education regarding the safe use of prescribed medications that are potentially addictive. For example, a treatment consumer reported: "And I also think that when a doctor prescribes these opiates, that doctor also need to explain that they are very addicting. When they gave me all my prescriptions, not one doctor came up to me and said, 'Oh, this is very addictive."' Treatment consumers and treatment providers suggested education on medication treatment for those needing help. "Educating people to what's available out there, as far as, like, medications and treatment" (treatment consumer).

\section{Judicial System}

The challenges to recovery within the judicial system were discussed. For one, it was difficult for individuals to stay drug free while incarcerated. "Jail's not going to do you any good, 'cause you can get high in jail... probably easier than you can on the street, at this point" (treatment consumer). Therefore, controlling the influx of illegal substances in prison was recommended. All groups discussed the impact of having a drug charge for individuals trying to make a positive change in their life. "And if you're giving them this drug record and they get out of jail and they can't get a job, so then what are they supposed to do?" (law enforcement). Treatment consumers, treatment providers, and law enforcement discussed decriminalization as a possible way to help: "So decriminalize ... Emphasize that it's a medical issue" (treatment providers). Concern about the overall cost for incarceration was discussed as well as the effectiveness of prison: "How much is it to arrest them and take them to jail and leave them sit there?" (law enforcement). All groups reported additional outside pressure, such as those from the judicial system, was sometimes necessary. A treatment consumer reported: “...but though I think you need a little more encouragement, such as: you are, you must do this. You must go in treatment. You must, or you, you know, you're never going to get off probation or whatever. Just, something to kick your butt."

Treatment consumers and providers discussed drug court and the treatment in jail that helped treatment consumers to become stable in recovery. "I attribute my sobriety, majority of it, now to, the TC [therapeutic community] program that I went through that is now offered within the prison system" (treatment consumer). Overall, all groups felt there needed to be programs in place for those who were in and/or interested in recovery and involved in the judicial system: “... people need opportunities for second chances" (treatment provider).

\section{Environmental Barriers}

Environmental barriers were discussed, including housing, employment, and transportation needs. Unfortunately, many of the treatment centers were not located along transportation routes that were accessible to treatment consumers, especially those in rural areas: "I've been payin' Uber and Lyft rides every day to get here and back... seventy or eighty [dollars] for the ride every day and fifteen for the juice [Methadone] when I get here. That's for me to stay clean, and you know, I'm lucky that I can do that. A lot of people can't afford that kind of thing" (treatment consumer).

In addition to the recommendations to bring more SUD treatment facilities to rural areas, which was mentioned by multiple participants, one treatment consumer had a recommendation to provide mobile treatment clinics similar to those provided for mammograms: “... it's already bad enough you don't want to have to come here. Then it was like, having to come here three times a week, three hours at a time, gas back and forth. You know, how they got those... mobile breast cancer vans? Maybe do like one of them for the outlying communities. So people don't have to travel as far."

As mentioned in the previous section, many participants discussed that felony drug convictions can severely limit employment and housing options, which led to recommendations of making it easier to have felony convictions expunged.

\section{Resources}

All groups had suggestions on resources that could help treatment consumers. These included case management, outreach, access to Narcan, advocacy, and funds. "Case management is so important, because you need someone to help you and guide you, let you know where those resources are" (treatment provider). Treatment consumers who experienced outreach talked about how it helped them to seek treatment, and more was needed. The need to access Narcan was important to all groups. All groups realized that funding for resources was needed, and thought that the public was onboard, but not necessarily the government. "Honestly, I think that if it was put on the ballot for an increase in funding, I think that it would pass in this area, because of how bad things are" (treatment provider). Treatment providers talked about advocating for the individuals they treated but saw little impact: "But is limited to our population because of the resources, the lack of resources, we need to move forward and address those and everybody comes to those meetings [meetings with legislators] and shakes their heads and says, 'Oh I didn't understand' but then nothing gets changed" (treatment provider). One law enforcement personnel suggested a way to access the money and resources needed: "So, it'd be nice if the state of Ohio somehow could, whether it was OMAS, or whether it was the governor, state legislator, someone could declare a health emergency. And have the resources on the street, to not only save lives but shift addiction." 


\section{Stigma}

Health-related stigma is a social process whereby social groups are devalued, rejected, blamed, and excluded on the basis of a socially discredited health condition or health-related problem. ${ }^{25}$ Treatment consumers reported the stigmatization they received as a group: “We've got a bad stigma on us and I don't think that, you know, we get a fair fighting chance because we've got so many people against us." Treatment providers and law enforcement agreed. A treatment provider summed up why treatment consumers face stigma: "I think a big problem in our state is that it is still seen as a moral issue ... Rather than a medical issue." Treatment consumers discussed how isolating it felt: "That's just, like, me personally like, for a minute, I just felt like I was in a black hole. I couldn't talk to anybody about this so I didn't talk to anybody about it. But it just made my addiction worse." Treatment providers and law enforcement saw this as impeding recovery, as they would go back to their previous lifestyle. "So they go right back to the people that they know, who will actually spend time with them. What are they doing? Probably drugs. They feel hopeless, so what do they want to do? Probably more drugs. We set the system up to just completely not support you in recovery, if you do get stuck in it" (law enforcement).

All groups discussed the need to support more drug-free activities to decrease the feelings of isolation. Additionally, recommendations were made to offer opportunities to prepare those in the community to support those with SUD: "I think there should be, like, class or meetings for people who are dealing with people who have addictions, more like empathy, compassion. Because a lot of these people, they don't feel like they have anyone they can turn to or talk to" (treatment consumer).

\section{Stages of Change}

The stages of change, applied to treatment consumers, is drawn from the transtheoretical model, conceptualizes behavior change as a process that unfolds over time, and involves a series of 5 stages: precontemplation, contemplation, preparation, action, and maintenance. ${ }^{26,27}$ All groups discussed the realized importance of the individual with SUD wanting to change: "He can throw me in jail a hundred times. If I'm not ready, I'm not gonna quit" (treatment consumer). They also discussed the challenges of continuing to maintain that substance-free lifestyle: "But it's, from what we see and it's almost... Like a revolving door" (law enforcement). The solution often suggested was making treatment available for longer periods of time: "But if I would have been at treatment for a full ninety days, I would have had more drive to continue my recovery" (treatment consumer).

\section{Treatment}

All groups had suggestions about treatment. Sober living opportunities for individuals in recovery were discussed in all groups: "Sober living that are MAT (medication-assisted treatment)friendly" (treatment provider). "You had a transitional living type o" sober living facility where they go in there and they stay there for six months" (law enforcement). Integrated care was discussed as a need: "Part of treatment is getting physically healthy ... So, getting people back in and seeing a doctor regularly" (treatment consumer). Treatment providers and consumers discussed how some programs only provided medication treatment but not counseling, so individuals do not get needed help. As a treatment consumer shared: "Cause the other place I was goin' in, you just pay 'em and got your medicine and then you left. I think there needs to be counseling, not just hand out the medication." Providers talked about their concern that there was a growth in different types of medication treatment but not one that has a history of success: "We, we got all these suboxone programs... Poppin' up everywhere for profit. But yet methadone is still the gold standard, for treating opioid addiction, but yet we still have the same regulations that have been in place for probably the last thirty years." Treatment consumers also discussed this challenge with methadone, leading to less methadone clinics: "Remove the tight, unyielding restrictions they've had on it since the sixties." Overall, all groups agreed treatment was essential to addressing drug abuse: "Treatment is the most powerful tool that can change lives" (treatment provider).

\section{DISCUSSION}

Substance use disorder is a common and under-treated problem that has a major impact on individuals, their families, and the community. While most research has focused on understanding the barriers to SUD treatment, qualitative studies have sought out suggestions and recommendations about SUD treatment and prevention among treatment consumers, treatment providers, and law enforcement,,38-30 but none have explored the perspectives of all 3 of these groups simultaneously.

Participants interviewed from all 3 groups shared recommendations within the same categories (education, judicial system, psychosocial barriers, resources, stigma, stages of change, and treatment) when asked what they would propose to the governor and other state officials regarding drug abuse and prevention. Similar to a recent study by Bunting and colleagues, ${ }^{29}$ the participants identified individual, interpersonal, institutional, organizational, and system-level barriers, yet were still able to provide systemlevel recommendations appropriate for public policy interventions.

Recommendations addressing access to care included helping individuals receive appropriate levels of treatment regardless of where they live, their insurance provider, or status. Suggestions regarding the judicial system included advocating for treatment over incarceration and using the judicial system for leverage when needed. Decriminalization and revoking drug felony convictions were frequent suggestions especially because of the limiting impacts felony convictions have for employment and housing. A possible solution to help treatment consumers in the judicial system is to connect them to a caseworker prior to being released. In Massachusetts, the Hampden County jail developed a program whereby health care teams worked within the correctional facility and the 
community to provide care for individuals during their release. ${ }^{31}$ By providing individuals with support to access resources, they may be more likely to become connected to services.

Recommendations for overcoming psychosocial barriers included decreasing transportation challenges through mobile treatment vans and providing treatment in rural areas. Efforts to address stigma included recommendations to offer more drug-free activities and targeted education efforts for community members with stigmatizing beliefs.

The importance of recognizing the readiness for individuals to seek treatment was a frequently mentioned concept in all groups, with recommendations to ensure that treatment is available when people are ready. For many individuals, readiness fluctuates over time, rather than being a linear experience, which underlies the importance of having treatment available on demand, as readiness may wane if too much time is allowed to pass before access to treatment is available. ${ }^{30}$

Finally, recommendations for treatment were suggested by all groups. This included increasing all levels of treatment; ie, medication treatment, sober living, and integrated health care. This echoes sentiment found by Browne and colleagues, whose participants suggested partnerships between care providers to ensure the holistic needs of individuals who use substances are met while also providing flexible agency operating times as a way for treatment to be accessible beyond typical business hours. ${ }^{28}$

\section{Limitations}

There were some limitations in this study. Focus groups varied in the number of participants. Also, participants self-selected to participate in the study. Social desirability may have impacted data provided by participants. Furthermore, generalizability of findings is limited due to convenience sample within a specific geographical location as well as the nature of qualitative research exploring more in-depth topics. Finally, demographic information on treatment providers and law enforcement officers was not collected.

\section{PUBLIC HEALTH IMPLICATIONS}

Public health can address SUD on micro, mezzo, and macro levels. Counselors who provide treatment can link clients to case management services or provide outreach to individuals who are actively using substances or have recently overdosed. For example, in Cincinnati's Colerain Township, the community paramedicine model is utilized, whereby a team of police officers, firefighters/ emergency medicine technicians (EMTs), and social workers make home visits within 1 week to an individual who overdosed and EMTs were called to the scene. ${ }^{32}$ School personnel such as counselors and health educators could help to design programs on SUD for parents and pupils, such as working with individuals in recovery to share their stories and providing parents with talking points to discuss SUD with their children. These interviews show that in addressing SUD, law enforcement, treatment providers, and treatment consumers are often in agreement over the im- portance of treatment options. Public health professionals could build coalitions with community groups and representatives from treatment providers and law enforcement to agree on options when addressing SUD. Furthermore, public health professionals can lobby legislators for funding to support treatment options, advocate for laws to reduce sentencing for drug use, and replace prohibitive regulations associated with methadone treatment to increase accessibility. Future public health researchers can design studies on the effectiveness of prevention and treatment options to determine impact.

\section{Conclusion}

Treatment consumers, treatment providers, and law enforcement officers are affected by complex issues of SUD on micro, mezzo, and macro levels. Yet these 3 groups identified possible solutions to address SUD. Public health professionals can help facilitate changes by advocating for prevention and intervention methods to be implemented to address SUD.

\section{ACKNOWLEDGMENTS}

The authors have no known conflict of interest to disclose. This research did not receive any specific grant from funding agencies in the public, commercial, or not-for-profit sectors.

\section{REFERENCES}

1. Substance Abuse and Mental Health Services Administration. Key Substance Use and Mental Health Indicators in the United States: Results from the 2018 National Survey on Drug Use and Health. HHS Publication No. PEP 19-5068, NSDUH Series H-54. Rockville, MD: Center for Behavioral Health Statistics and Quality, Substance Abuse and Mental Health Services Administration, 2019. Accessed March 31, 2021. https://www.samhsa.gov/data/sites/default/files/cbhsq-reports/ NSDUHNationalFindingsReport2018/NSDUHNationalFindingsReport 2018.pdf

2. Schulte MT, Hser YI. Substance use and associated health conditions throughout the lifespan. Public Health Rev. 2014;35(2).

https://doi.org/10.1007/BF03391702

3. Green TC, Zaller N, Palacios WR, et al. Law enforcement attitudes toward overdose prevention and response. Drug Alcohol Depend. 2013;133(2):677-684. https://doi.org/10.1016/j.drugalcdep.2013.08.018

4. Jorgensen C. Badges and bongs: Police officers' attitudes toward drugs. SAGE Open. October 2018. https://doi.org/10.1177/2158244018805357

5. Kerr T, Small W, Wood E. The public health and social impacts of drug market enforcement: a review of the evidence. Int J Drug Policy. 2005;16(4), 210-220. https://doi.org/10.1016/j.drugpo.2005.04.005

6. Barbosa C, Cowell A, Dowd W, Landwehr J, Aldridge A, Bray J. The costeffectiveness of brief intervention versus brief treatment of Screening, Brief Intervention and Referral to Treatment (SBIRT) in the United States. Addiction. 2017;112 Suppl 2:73-81. https://doi.org/10.1111/add.13658

7. Moore DJ. A nurse practitioner's perspective on prescribing suboxone for opioid use disorder. J Addict Nurs. 2018;29(3):226-229. https://doi.org/10.1097/JAN.0000000000000242 
8. Palumbo R. A call to action: Defining the acute care nurse's role in harm reduction for persons with substance use disorder. J Addict Nurs. 2019;30(4):236-237. https://doi.org/10.1097/JAN.0000000000000304

9. BC Centre for Disease Control. Understanding Harm Reduction: Substance Use [102a]. HealthLinkBC; 2020. Accessed March 31, 2021. https://www.healthlinkbc.ca/hlbc/files/documents/healthfiles/ hfile102a.pdf

10. Kidorf M, Latkin C, Brooner RK, Yan H, Peirce J. Developing a community-supported risk reduction intervention for syringe exchange registrants and their drug-free family or friends: A pilot study. J Addict Dis. 2021;39(2):248-256. https://doi.org/10.1080/10550887.2020.1854033

11. Ohio Department of Health. Drug overdose. January 4, 2021. Accessed March 31, 2021. https://odh.ohio.gov/wps/portal/gov/odh/know-our-programs/ violence-injury-prevention-program/Drug-overdose/

12. Centers for Disease Control and Prevention and National Center for Health Statistics. CDC WONDER: Multiple cause of death 1999-2018. cdc.gov; Accessed March 31, 2021. https://wonder.cdc.gov/mcd-icd10.html

13. Hedegaard H, Bastian BA, Trinidad JP, Spencer MR, Warner M. Regional differences in the drugs most frequently involved in drug overdose deaths: United States, 2017. Natl Vital Stat Rep. 2019;68(12):1-16. Accessed March 31, 2021. https://www.cdc.gov/nchs/data/nvsr/nvsr68/nvsr68_12-508.pdf/

14. Ohio Department of Mental Health and Addiction Services. Ohio Substance abuse Monitoring (OSAM). Accessed March 31, 2021. https://mha.ohio.gov/Researchers-and-Media/Workgroups-andNetworks/Ohio-Substance-Abuse-Monitoring-Network

15. Ohio Public Health Data Warehouse. Ohio Resident Mortality Data, 2018. Publicapps.odh.ohio.gov. Accessed March 31, 2021. https://publicapps.odh.ohio.gov/EDW/DataCatalog

16. Pullen E, Oser C. Barriers to substance abuse treatment in rural and urban communities: counselor perspectives. Substance Use \&Misuse. 2014;49(7):891-901. https://doi.org/10.3109/10826084.2014.891615

17. Henderson CE, Taxman FS. Competing values among criminal justice administrators: the importance of substance abuse treatment. Drug Alcohol Depend. 2009;103 (Suppl 1):S7-S16. https://doi.org/10.1016/j.drugalcdep.2008.10.001

18. Siegal HA, Carlson RG, Kenne DR, Starr S, Stephens RC. The Ohio Substance Abuse Monitoring Network: constructing and operating a statewide epidemiologic intelligence system. Am J Public Health. 2000;90(12):1835-1837. https://doi.org/10.2105/ajph.90.12.1835

19. Onwuegbuzie AJ, Dickinson WB, Leech NL, Zoran AG. A quantitative framework for collecting and analyzing data in focus group research. Int J Qual Methods. 2009;8(3): 1-21. https://doi.org/10.1177/160940690900800301

20. Cho JY, Lee EH. Reducing confusion about grounded theory and qualitative content analysis: similarities and differences. Qual Rep. 2014;19 (32). https://doi.org/10.46743/2160-3715/2014.1028
21. Elo S, Kyngäs $\mathrm{H}$. The qualitative content analysis process. JAdV Nurs. 2008;62(1):107-15. https://doi.org/10.1111/j.1365-2648.2007.04569.x

22. Carter N, Bryant-Lukosius D, DiCenso A, Blythe J, Neville AJ. The use of triangulation in qualitative research. Oncol Nurs Forum. 2014;41

(5):545-7. https://doi.org/10.1188/14.0NF.545-547

23. Miles M, Huberman A. Qualitative Data Analysis. London: SAGE Publishing; 1994.

24. Morse JM. Critical analysis of strategies for determining rigor in qualitative inquiry. Qual Health Res. 2015;25(9):1212-1222. https://doi.org/10.1177/1049732315588501

25. Weiss MG, Ramakrishna J, Somma D. Health-related stigma: rethinking concepts and interventions. Psychol Health Med. 2006;11(3):277-287. https://doi.org/10.1080/13548500600595053

26. Prochaska, JO, DiClemente, CC. The Transtheoretical Approach: Crossing the Traditional Boundaries of Therapy. In: Homewood, IL: Dow Jones-Irvin. 1984.

27. DiClemente CC, Schlundt D, Gemmell L. Readiness and stages of change in addiction treatment. Am J Addict. 2004;13(2):103-119. https://doi.org/10.1080/10550490490435777

28. Browne T, Priester MA, Clone S, Iachini A, DeHart D, Hock R. Barriers and facilitators to substance use treatment in the rural south: a qualitative study. J Rural Health. 2016;32(1):92-101. https://doi.org/10.1111/jrh.12129

29. Bunting AM, Oser CB, Staton M, Eddens KS, Knudsen H. Clinician identified barriers to treatment for individuals in Appalachia with opioid use disorder following release from prison: a social ecological approach. Addict Sci Clin Pract. 2018;13(1):23. https://doi.org/10.1186/s13722-018-0124-2

30. Redko C, Carlson RG, Rapp RC. A folk model of treatment readiness among drug users in Ohio. JEthn Subst Abuse. 2007;6(2):15-40. https://doi.org/10.1300/J233v06n02_03

31. Wang EA, Hong CS, Shavit S, Sanders R, Kessell E, Kushel MB. Engaging individuals recently released from prison into primary care: a randomized trial. Am J Public Health. 2012; 102:e22-e29. https://doi.org/10.2105/AJPH.2012.300894

32. University of Cincinnati Fire Science Program. Attacking the overdose epidemic with community paramedicine. EMS World. March 5, 2017. Accessed March 31, 2021.

https://www.emsworld.com/news/12312054/attacking-theoverdose-epidemic-with-community-paramedicine 